\title{
Developmental Trajectories of Childhood Obesity and Risk Behaviors in Adolescence
}

\author{
David Y.C. Huanga ${ }^{a}$ H. Isabella Lanza ${ }^{b}$, Kynna Wright-Volel' , and M. Douglas Anglin ${ }^{d}$ \\ aUCLA Integrated Substance Abuse Programs, Semel Institute for Neuroscience and Human \\ Behavior, 11075 Santa Monica Blvd., Suite 200, Los Angeles, CA 90025, USA, \\ yhuang@ucla.edu \\ bUCLA Integrated Substance Abuse Programs, Semel Institute for Neuroscience and Human \\ Behavior, 11075 Santa Monica Blvd., Suite 200, Los Angeles, CA 90025, USA, hilanza@ucla.edu \\ 'UCLA School of Nursing, 5-157 Factor Building, 700 Tiverton Ave., Los Angeles, CA \\ 90095-6919, USA, kwright@sonnet.ucla.edu \\ dUCLA Integrated Substance Abuse Programs, Semel Institute for Neuroscience and Human \\ Behavior, 11075 Santa Monica., Suite 200, Los Angeles, CA 90025, USA, \\ doug_anglin@hotmail.com
}

\section{Introduction}

The prevalence of childhood obesity has substantially increased in recent decades with current estimates indicating that $16.9 \%$ of children and adolescents in the United States are obese (Ogden, Carroll, Curtin, Lamb, \& Flegal, 2010). This heightened prevalence is concerning as numerous studies have found that childhood obesity confers risk for various physical health conditions (Craig, Love, Ratcliffe, \& McNeill, 2008; Rosenbloom et al., 2008), and poorer psychosocial outcomes (Needham, Epel, Adler, \& Kiefe, 2010; Pearce, Boergers, \& Prinstein, 2002; Sweeting, Wright, \& Minnis, 2005; Zeller, Reiter-Putrill, \& Ramey, 2008). However, relatively few studies have examined relations between childhood obesity and other behavioral risks in adolescence (e.g., substance use and delinquency). The identification of links between obesity and risk behaviors could inform prevention and intervention efforts to decrease health-risk behaviors during adolescence, a developmental period typically characterized by increased risk-taking (Steinberg, 2008).

Associations between obesity and substance use (i.e., alcohol, tobacco, and other drug use) are relatively limited, but some cross-sectional studies have reported positive associations between overweight/obesity status in adolescence and both alcohol use and cigarette smoking (Farhat, Iannotti, \& Morton-Simons, 2010; Fonseca, Matos, Guerra, \& Pedro, 2009; Oesterle et al., 2004; Ratcliff, Jenkins, Reiter-Purtill, Noll, \& Zeller, 2011; Leatherdale, Wong, Manske, \& Colditz, 2008; Potter, Pederson, Chan, Aubut, \& Koval, 2004). Available longitudinal studies on child obesity and risk behaviors have shown less

(c) 2012 The Association for Professionals in Services for Adolescents. Published by Elsevier Ltd. All rights reserved.

Corresponding author: David Y.C. Huang, UCLA Integrated Substance Abuse Programs, Semel Institute for Neuroscience and Human Behavior, 11075 Santa Monica Blvd., Suite 200, Los Angeles, CA 90025, USA. Phone: +1 (310) 267-5288; Fax: +1 (310) 473-7885, yhuang@ucla.edu.

Publisher's Disclaimer: This is a PDF file of an unedited manuscript that has been accepted for publication. As a service to our customers we are providing this early version of the manuscript. The manuscript will undergo copyediting, typesetting, and review of the resulting proof before it is published in its final citable form. Please note that during the production process errors may be discovered which could affect the content, and all legal disclaimers that apply to the journal pertain. 
consistent results. Pasch and colleagues (Pasch, Nelson, Lytle, Moe, \& Perry, 2008) found that early substance use predicted an increase in weight status, but increased weight status did not predict substance use in a sample of early adolescents. Two studies, one following a sample from early to mid-adolescence (Caria, Bellocco, Zambon, Horton, \& Galanti, 2009) and another assessing an adolescent cohort (age 12-21) across three years (Cawley, Markowitz, \& Tauras, 2004), reported that smoking initiation was more likely among girls, but not boys, who were overweight or obese. The small amount of empirical work evaluating obesity and delinquency has reported both a non-significant association among adolescents (Ho, Kingree, \& Thompson, 2006) and a positive association among boys (Pine et al., 1996). Clearly, there is a dearth of literature on obesity and risk behaviors, with most studies being limited by their cross-sectional nature or longitudinal studies not addressing whether transitional patterns of obesity status from childhood to adolescence influence risk behavior engagement.

Research investigating the patterns, timing, and covariates of childhood obesity has generally been restricted by a lack of longitudinal data with samples large enough to conduct advanced statistical modeling, and also by a reliance on examining an "average" trajectory of BMI across the population. In the last decade, however, the availability of data and development of person-centered approaches have resulted in a growing number of obesity trajectory modeling studies (Li, Goran, Kaur, Nollen, \& Ahluwalia, 2007; Mustillo, Worthman, Erkanli, Keeler, \& Angold, 2003; Nonnemaker, Morgan-Lopez, Pais, \& Finkelstein, 2009; Ventura, Loken, \& Birch, 2009). With these advances, an examination of obesity trajectories from early childhood to late adolescence in a nationwide sample of youth is possible and warranted, not only to elucidate associations between obesity and psychosocial health but also to gain a more comprehensive understanding of obesity and psychosocial health. Although links between obesity and psychosocial indicators, including self-esteem, peer and romantic relationships are widely studied, and there is consensus that obese adolescents are at greater risk for poor social-emotional outcomes (Crosnoe \& Muller, 2004; Pearce, et al., 2002; Sweeting et al., 2005; Zeller et al., 2008), it is unclear whether particular obesity trajectories (e.g., chronic vs. late-onset obesity) are more or less related to psychosocial maladjustment in adolescence.

Using data from the 1979 National Longitudinal Survey of Youth (NLSY79) child sample, the current study sought to: (1) depict developmental pathways of obesity from early childhood to late adolescence (ages 6 to 18); (2) examine associations of such trajectories with psychosocial indicators; and (3) determine whether specific obesity trajectories are associated with greater trends in risk behaviors across adolescence. We expected that trajectories would not only differentiate obese from non-obese children, but also distinguish obesity status by onset and duration to form trajectory groups representing those who are chronically obese across childhood and adolescence as well as groups characterized by increasing or decreasing over time. We hypothesized that adolescents meeting obesity status across childhood and adolescence (e.g., chronically obese) will report poorer psychosocial health status and higher levels of risk behaviors across adolescence.

\section{Methods}

\section{Sample}

The child sample of the 1979 National Longitudinal Survey of Youth (NLSY79; U.S. Department of Labor, 2011) was used. The original NLSY79 consists of 12,686 young men and women who were 14-22 years old when they were first surveyed in 1979. The child survey provides developmental assessment of children born to female NLSY79 respondents, including height and weight, school and social experiences, behavior problems, and healthrisk behaviors. Measures were obtained through mother and child interviews. Children $\geq 10$ 
years were administrated standardized assessments of depression, self-esteem, and selfcontrol, and self-reported information on schooling, social relationships, problem behaviors, and substance use. Beginning in 1994, children $\geq 15$ years were given a questionnaire with a focus on transition from adolescence to young adulthood, including measures on education and employment, as well as risk behaviors related to sexual activity, delinquency, and substance use.

Data on children have been collected biennially since 1986 with most recent data collected in 2008. Twelve waves of data (1986 to 2008) were analyzed. In 1986, a total of 4,971 children born to NLSY79 mothers were interviewed. Newborn children were added in each subsequent wave. By 2008, a total of 11,495 children had participated. To ensure sufficient data on each child to estimate his/her developmental obesity trajectory (from ages 6-18), this study examined the 5,156 children (2,579 boys and 2,577 girls; $41.7 \%$ White, $34.9 \%$ African American, $21.6 \%$ Hispanic, and $1.8 \%$ other) who completed 8 or more waves of surveys from 1986 through 2008 . Table 1 presents the number of children who had a measure of obesity status from ages 6 to 18 .

\section{Measures}

Obesity status-Using self-report of weight and height at each interview, obesity status was measured with the Body Mass Index (BMI; $\mathrm{kg} / \mathrm{m}^{2}$ ), a standard measure for classifying individuals as overweight or obese (Barlow et al., 2007). At each assessment point, BMI was standardized into an age- and gender-specific BMI percentile using the Centers for Disease Control and Prevention (CDC) 2000 growth charts (Kuczmarski et al., 2000). Obesity at each assessment point was defined as having a BMI percentile at or above $95 \%$. To examine obesity status from ages 6 to 18, obesity status across the 12 waves of data were temporally rearranged based upon the participant's age at each interview. Since children were surveyed biennially, the age interval is an increment of 2 years.

Self-Esteem-The Rosenberg Self-Esteem scale (Rosenberg, 1965) was administered to children $\geq 15$ years. Children reported on 10 items (e.g., "I am a person of worth" and "I feel that I am a failure") using a 4-point scale ( $1=$ strongly disagree to $4=$ strongly agree). Sum of item responses ranged from 10 to 40 with higher scores reflecting greater self-esteem. The Cronbach alpha across waves was 0.87 , ranging from 0.85 to 0.88 for each wave. Multiple scores obtained from ages 15 to 18 were averaged as an indicator of self-esteem. Using a median split, a score $\geq 34$ indicated a high level of self-esteem.

Self-control-The Pearlin Mastery Scale (Pearlin, Menagham, Lieberman, \& Mullan, 1981) was administered to children $\geq 15$ years. Children reported on 7 items (e.g., "There is no way I can solve the problems I have" and "I sometimes feel I am being pushed around") using a 4-point scale $(1=$ strongly disagree to $4=$ strongly agree $)$. Sum of item responses ranged from 7 to 28 with higher scores indicating greater self-control. The Cronbach alpha across waves was 0.75 , ranging from 0.70 to 0.77 for each wave. The average score of multiple assessments from ages 15 to 18 was used as an indicator of self-control. Using a median split, a score $\geq 22$ indicated a high level of self-control.

Depression-Children $\geq 15$ years reported on depressive symptoms using a 7-item version of the Center for Epidemiological Studies-D (CES-D) scale (Radloff, 1977). Sample items include endorsement of "trouble keeping mind on tasks" and "feeling depressed" using a 4point scale $(0=$ none of time to $3=$ most of time). Sum of item responses ranged from 0 to 21 with higher scores indicating greater depressive symptoms. The Cronbach alpha across waves was 0.69 , ranging from 0.74 to 0.66 for each wave. The average score from multiple assessments between ages 15 to 18 was used as an indicator of depressive symptoms. A high 
level of depression was determined using a score of 7 or greater; approximately, $20 \%$ of individuals would be expected to score in this range in a general population.

School experiences and expectations-Children $\geq 10$ years reported on satisfaction with school ( $1=$ very dissatisfied to $4=$ very satisfied $)$, and whether they had repeated a grade or skipped a grade. In addition, children $\geq 15$ indicated their educational expectations regarding the highest grade they would like to, and thought they would, complete. The information across multiple waves of survey was examined and integrated to indicate each adolescent's school experience (e.g., ever repeated a grade) and expectation (e.g., ever expect to go college).

Friendship and peer pressure-Children 10 to 14 years were asked how many close friends they had, whether they felt lonely $(1=$ hardly ever, $2=$ sometimes and $3=$ often $)$, and whether they felt pressure from friends to engage in behaviors $(0=$ no and $1=y e s)$, including working hard in school, smoking, trying illicit drugs, drinking alcohol, skipping school, and committing a crime. The reported information from ages 10 to 14 was examined for determining whether adolescents ever feel pressure from their peers in adolescence.

Dating and sexual behaviors-Children 10 to 14 years were asked at what age they first dated and frequency of dating. From age 15, participants reported their sexual activities at each wave of the survey, including age of first sexual intercourse, number of sexual partners in the past 12 months, and whether a condom was used during most recent sex. The information across multiple waves of survey was checked for determining the initial ages of dating and sexual activity.

Substance use-Children $\geq 10$ years reported whether they had ever used alcohol, cigarettes, or marijuana, and if so, age of first use, most recent use, and frequency of use in the past 30 days for each type of substance. They were also asked for the number of alcoholic drinks and cigarettes they had consumed per day in the past 30 days. Status of each type of substance use from ages 14 to 20 were utilized for examining trajectories of each substance use over time.

Delinquency-Children $\geq 15$ years were asked whether they had ever been involved in deviant behaviors (e.g., skipping school without permission; got drunk) and various criminal activities (e.g., stealing, property crimes, attack on others, and selling illicit drugs), and the number of times of involvement since the last interview. Multi-wave of information was used to assess delinquency engagement across age.

\section{Analyses}

Trajectory modeling in conjunction with multivariate comparisons of adolescents' characteristics, psychosocial health, and risk behaviors across adolescence with identified trajectory groups was conducted. First, the SAS PROC TRAJ procedure (Jones, Nagin, \& Roeder, 2001) for group-based trajectory modeling was applied to identify distinctive trajectory patterns of obesity from ages 6 to 18. The model identifies distinctive personbased clusters of individuals with homogeneous longitudinal trajectories (Nagin, 2005). The dependent variable was presence or absence of obesity at each age interval ( 2 years). Trajectories of obesity status across age were indicated by curvilinear curves with intercept, slope, and quadratic parameters and were estimated by a logit model with $\mathrm{j}$ trajectory groups. The model also included gender as a time-invariant covariate that affected probability of group membership. Each individual was placed into one trajectory group based upon estimated membership probabilities. A series of models were fitted with a sequential increase of groups (i.e., $j=2,3,4,5,6$ ). Goodness of model fit was evaluated 
with the Bayesian Information Criterion (BIC; Schwartz, 1978); with a higher BIC value indicating a better model fit. The optimal model should have a reasonably high BIC value, and identified trajectories should be distinct and interpretable.

Additionally, difference on each measure of adolescent characteristics and psychosocial health among the identified obesity trajectories was separately examined with the chi-square for categorical variables and multivariate analyses (e.g., SAS PROC GLM) for continuous variables. Substance use and delinquency measured across multiple assessments from ages 14 to 20 were examined as trends. The trend of each risk behavior was separately estimated using a growth curve model. The relationship of each risk behavior and age was established as a curvilinear trend with a random intercept and a random slope parameter. The intercept indicated initial level of risk behavior involvement at age 14 and the slope indicated rate of change of risk behavior involvement from ages 14 to 20 . The model also included the identified obesity trajectory groups from the group-based trajectory modeling as timeinvariant covariates. Using the non-obese trajectory as a reference group, three dummy indicators were created to indicate Chronically-obese, Decreasing, and Increasing trajectories. Estimates of these parameters represent intercepts and slopes of linear trend of each risk behavior for the trajectory groups. Equivalences of intercepts and slopes of linear trends among the trajectory groups were also tested. Each growth curve model was estimated using SAS PROC MIXED procedure.

\section{Results \\ Obesity Trajectories}

A series of group-based trajectory models, from a two- to a six-trajectory model, were fitted to identify the optimal model of obesity trajectories across childhood and adolescence. The $\mathrm{BIC}$ value increased from $\mathrm{BIC}=-9297.0$ in the two-trajectory model, to $\mathrm{BIC}=-9026.1$ in the four-trajectory model and BIC $=-9019.9$ in the five-trajectory model (the six-trajectory model did not converge). The reasonably high BIC values in the four- and five-trajectory models indicated that they were potential optimal models. Because the five-trajectory model included a trajectory with a very small subset of participants (2.6\%) and a non-interpretable curve, and the four-trajectory model had meaningful trajectories, the four-trajectory model was chosen as the best fitting model. Figure 1 shows trajectories of estimated obesity status of the four-trajectory model. About $8.5 \%$ of adolescents were classified in the Chronically Obese group; individuals remained at a high level of risk of obesity from ages 6 to 18 . Another 5.7\% were classified into the Decreasing group; individuals were obese in childhood but obesity risk decreased in early adolescence (after age 10). Another $5.1 \%$ were classified into the Increasing group; individuals were not obese in childhood (prior to age 10), but obesity risk increased from early (ages 10-14) to late adolescence (ages 15-18). The majority of individuals ( $80.7 \%$ ) belonged to the Non-obese group, representing those who did not meet obesity status throughout childhood and adolescence.

\section{Adolescent Characteristics and Psychosocial Health by Obesity Trajectory Groups}

Table 2 summarizes adolescents' characteristics and psychosocial health by the four obesity trajectories. Gender $\left(\chi_{(3)}^{2}=25.4, p<0.01\right)$ and ethnicity $\left(\chi_{(9)}^{2}=55.6, p<0.01\right)$ significantly differed among the four trajectory groups. Females were overrepresented in the Decreasing group. Males were more likely to belong to the Chronically Obese and Increasing groups. African-American adolescents were overrepresented in the Chronically Obese, Increasing, and Decreasing groups. White adolescents were more likely to belong to the Non-obese group. 
In terms of psychosocial indicators, adolescents in the Increasing group were less likely to exhibit high levels of self-esteem; conversely, adolescents in the Decreasing group were more likely to exhibit high levels of self-esteem $\left(\chi_{(3)}^{2}=11.2, p=0.01\right)$. Similarly, adolescents in the Increasing and Decreasing groups were less likely and more likely, respectively, to exhibit high levels of self-control $\left(\chi^{2}{ }_{(3)}=14.9, p<0.01\right)$. Although the Chronically Obese and Increasing groups consisted of greater proportions of adolescents exhibiting higher levels of depressive symptoms, depressive symptoms were not significantly related to a distinctive obesity trajectory.

Adolescents in the Increasing trajectory, compared to other trajectories, were more likely to repeat a grade $\left(\chi_{(3)}^{2}=20.9, p<0.01\right)$. Additionally, relative to adolescents in the Decreasing or Non-obese trajectories, fewer adolescents in the Chronically Obese or Increasing trajectories reported an expectation of going to college $\left(\chi_{(3)}^{2}=19.3, p<0.01\right)$.

Adolescents in the Increasing trajectory group were more likely to feel lonely compared to adolescents in other groups $\left(\chi_{(3)}^{2}=14.0, p<0.01\right)$. Compared to adolescents in the Nonobese trajectory, adolescents in the Chronically Obese, Decreasing, or Increasing trajectories were more likely to experience peer pressure regarding greater cigarette use $\left(\chi^{2}{ }_{(3)}=8.7, p=\right.$ 0.03). Likewise, adolescents in the Chronically Obese and Increasing trajectories were more likely to feel peer pressure to engage in delinquent activity compared to those in the Decreasing and Non-obese trajectories $\left(\chi_{(3)}^{2}=12.1, p<0.01\right)$. In terms of dating and sexual relations, those in the Chronically Obese trajectory had the smallest proportion of dating initiation by age $14\left(\chi_{(3)}^{2}=13.7, p<0.01\right)$ and also the lowest dating frequency $\left(\chi_{(3)}^{2}=\right.$ $23.8, p<0.01)$.

\section{Trends of Substance Use and Delinquency by Obesity Trajectory Groups}

The co-occurrence of obesity with such risk behaviors as alcohol use, cigarette smoking, marijuana use, and delinquency during adolescence was examined by comparing trends of risk behaviors from ages 14 to 20 across the four obesity trajectories. Estimated trend of each risk behavior is presented in Table 3. Figure 2A (Model A) indicates trends of alcohol use. Initial rate of alcohol use at age 14 in the Chronically Obese group (0.22) was lower than the Non-obese group $(0.27 ; p=0.03)$. Alcohol use increased over time, with similar accelerating rates among the four trajectory groups. In terms of binge drinking, consumption of 5 or more drinks per day increased over time among all groups, but was significantly lower among the Chronically Obese group (0.02) than the Non-obese group $(0.03 ; p=0.02)$.

The cigarette smoking rate (Model B; Figure 2B) at age 14 was lowest in the Chronically Obese group ( 0.12 vs. 0.17 for Non-obese; $p=0.01$ ), and highest in the Decreasing group ( 0.22 vs. 0.17 for Non-obese; $p=0.02$ ). The smoking rate accelerated from ages 14 to 20 across all groups, but adolescents in the Chronically Obese group exhibited a significant increase in smoking over time $(0.051)$ compared to the Non-obese $(0.035 ; p<0.01)$ and Decreasing $(0.03 ; p<0.01)$ groups.

Prevalence of marijuana use (Model C; Figure 2C) increased across age among all groups. In contrast to the other three groups, adolescents in the Chronically Obese group exhibited the lowest rate of marijuana use, but this was not statistically significant.

Figure 2D (Model D) illustrates rates of delinquency involvement by trajectories. Adolescents in the Chronically Obese and Non-obese groups, compared to the Increasing and Decreasing groups, were less likely to engage in delinquency at age 14 and also exhibited the most stable rate of change in delinquency across age. Adolescents in the Increasing group, in contrast to the Non-obese group, exhibited a higher likelihood of delinquency involvement at age 14 ( 0.64 vs. 0.54 for Non-obese; $p=0.01)$, but that was 
accompanied with a greater decrease across time ( -0.034 vs. -0.008 for Non-obese; $p<$ $0.01)$.

\section{Discussion}

Childhood obesity and risk behaviors in adolescence are major public health issues facing the nation (Ogden et al., 2010; Farhat et al., 2010; Steinberg, 2008). This study sought to contribute to the field of public health by extending the limited but growing literature on childhood obesity as it relates to risk behaviors by using group-based trajectory modeling to identify trajectories of obesity across childhood and adolescence and examine trajectoryspecific associations with risk behavior engagement across adolescence. It appears that chronic obesity is associated with a greater rate of cigarette smoking in adolescence. However, obesity status was generally unrelated to higher risk of alcohol and marijuana use, as well as delinquency. Furthermore, the identified obesity trajectories differentiated adolescents' psychosocial health status. Specifically, adolescents moving into obesity status during adolescence were more likely to experience poorer psychosocial health. These findings provide a better understanding of complex interrelationships among obesity and risk behaviors, and advocate enhanced public health interventions during the vulnerable transition between childhood and adolescence to offset potential negative psychosocial consequences of obesity.

The four obesity trajectories revealed that about $9 \%$ of the sample were chronically obese across childhood and adolescence, roughly another $11 \%$ transitioned into and out of obesity status during early adolescence, and most $(80 \%)$ were not obese at any time point. These four patterns are comparable to those previously identified (Mustillo et al., 2003), which utilized a similar developmental range (ages 9 to 16 ) to examine obesity trajectories. The prevalence of obesity in this sample is similar to prior findings indicating 19\% of 6 to 19 year-olds meet obesity status (Ogden et al., 2010). In addition, taking into account the age overlap, our trajectories are in line with the previously identified early-onset, late-onset, and never overweight obesity groups among children (Li et al., 2007), which are similar to our chronic, increasing, and non-obese groups. Furthermore, the trajectory groups identified by Nonnemaker et al. (2009) showing risk of obesity across adolescence to young adulthood ranging from low to high corroborates the heterogeneity of obesity patterns in the current study. In sum, this work extends prior obesity trajectory studies by including time points from early childhood to late adolescence, which allows a closer examination of the transition from childhood to adolescence, a critical period for socio-emotional development that may particularly impact obese individuals. Also, gender and racial/ethnic differences by obesity trajectory were found in line with past research (Ogden et al., 2010), indicating that males are more likely to be chronically obese and transition into obesity during adolescence than females, and White adolescents are less likely to be obese than African-American and Hispanic adolescents. The ethnic differences may partially reflect socioeconomic disparity, as African-American and Hispanic adolescents are more likely to live in lower socioeconomic status than White adolescents, which may impede their healthy nutritional intake and physical activity (Caprio et al., 2008; Gordon-Larsen, Adair \& Popkin, 2003).

This study significantly adds to the limited research on obesity and risk behaviors in adolescence by examining trends of risk behaviors across adolescence by different obesity trajectories. Trends revealed that the Chronically Obese group reported a greater increase in cigarette smoking over time than the Decreasing and Non-obese groups. However, increased trends in alcohol, marijuana use, and delinquency was found to be similar across trajectory groups, suggesting that positive association between obesity and risk behaviors may be specific to cigarette smoking. This is in line with a previous study (Nonnemaker et al., 2009) examining substance use behaviors by obesity trajectory, which revealed that those with 
low-to-moderate and moderate-to-high obesity risk had a higher probability of being a current smoker than the low risk group and also indicated no significant associations with binge drinking or marijuana use. There are several explanations for why chronic obesity is specifically associated with an increased rate of smoking across adolescence. Potentially life stressors may be an underlying marker of both obesity and smoking, as a wealth of literature has shown stress to elicit both obesogenic eating behaviors (Oliver, Wardle, \& Gibson, 2000; Schiffman, Graham, Sattely-Miller, \& Peterson-Dancy, 2000; Torres \& Nowson, 2007) as well as increased cigarette smoking (Byrne, Byrne, \& Reinhart, 1995; Lloyd \& Taylor, 2006; Willis, Sandy, \& Yaeger, 2006) among adolescents. Peer influence also has been highlighted as a key factor contributing to adolescent smoking (see review: Kobus, 2003), which may encourage obese adolescents to engage in smoking in order to increase their poor social status among peers. Another explanation stems from the finding that adolescents in the Decreasing group reported the highest rate of smoking at age 14 compared to all other groups, suggesting that obese adolescents may be using cigarette smoking as a weight-management coping strategy, as reported previously (Lowry, Galuska, Fulton, Wechsler, \& Kann, 2002; Potter et al., 2004). Additionally, adolescents in the Increasing group exhibited the highest likelihood of delinquency involvement at age 14, followed by the greatest decrease in delinquency from ages 14 to 20, implying that the emergence of obesity in adolescence coincides with a decreased likelihood of delinquency. It is possible that adolescents becoming obese during adolescence may have fewer opportunities to engage in social activities with others, including less exposure to deviant behaviors conducted in social setting with peers (Ratcliff et al., 2011).

Findings also suggest that changes in body size from childhood to adolescence are associated with psychosocial health. Adolescents in the Increasing group generally reported poorer psychosocial health, including lower self-esteem, lower self-control, poorer school expectations and experiences, and greater loneliness. On the other hand, adolescents in the Decreasing group were more likely to exhibit higher levels of self-esteem and self-control. Besides dating less than other groups, Chronically Obese adolescents did not have lower levels of psychosocial functioning than non-obese individuals. To date, only one other study has compared psychosocial outcomes among obesity groups identified from a rural white youth sample, and the study showed that adolescents in the Chronic obesity group had higher likelihood of externalizing and internalizing disorders (oppositional defiant disorder and depression) than other groups (Mustillo et al., 2003). Although this is different from our findings, the two studies consisted of different ethnic compositions and the current study did not examine psychiatric symptoms. The lack of prior findings warrants further investigation on health outcomes for chronically obese youth.

One explanation for these findings highlighting the Increasing group as most vulnerable is recognizing that the transition from childhood to adolescence is characterized by significant identity development largely influenced by heightened social awareness (Brown, 2004). A sense of belongingness and social standing is critically important to adolescents (LaFontana \& Cillessen, 2010), and obese adolescents may experience social rebuff for not fitting in with their peers in terms of physical appearance (Strauss \& Pollack, 2003), which contributes to poorer psychosocial outcomes (Pearce et al., 2002; Sweeting et al., 2005). Thus, adolescents becoming obese in early adolescence (i.e., Increasing group) likely are met with greater social stigmatization and accompanying poorer psychosocial health. Conversely, social relationships may not be as impacted among chronically obese adolescents because their onset of obesity emerges prior to heightened salient of social status; therefore, they may have better opportunities to form and maintain relationships before peers place more importance on physical appearance. Furthermore, we cannot exclude the possibility that the association between adolescent-onset obesity and poorer psychosocial health is explained by a shared underlying marker, such as a disruption to the 
family environment (e.g., family conflict, divorce) during the period of early adolescence. Decreases in parental monitoring and responsiveness resulting from a disruption are likely to negatively impact children's eating habits in ways increasing obesity risk (Arkes, 2012; Rhee, Lumeng, Appugliese, Kaciroti, \& Bradley, 2006), as well as increasing children's internalizing symptoms (Langenkamp, \& Frisco, 2008; Oldehinkel, Ormel, Veenstra, De Winter, \& Verhulst, 2008). In any case, psychosocial prevention and intervention efforts should aim to promote self-esteem among adolescents in the Increasing trajectory group, which may have a substantial positive long-term effect (Haney \& Durlak, 1998; McVey, Davis, Tweed, \& Shaw, 2004). In addition to increase adolescents' knowledge about healthy behaviors, enhance their activity level, and improve their nutritional intake, an integrated intervention program may aim to enhance self-esteem by providing additional familial and school supports to such high-risk adolescents.

\section{Limitations}

Despite the significant findings of this study, there are limitations. First, the study sample consists of children from three birth cohorts; $17.2 \%, 74.9 \%$ and $7.9 \%$ were from the $1970 \mathrm{~s}$ (1970-1979), 1980s (1980-1989) and 1990s (1990-1992) birth cohorts, respectively. Distributions of obesity trajectories were slightly different among the three birth cohorts. Children in the 1990s birth cohort $(9.1 \%)$ were more likely to belong to the Decreased trajectory than children in the 1970s (3.2\%) and the 1980s cohorts (5.9\%). However, a sensitivity analysis on obesity trajectories including birth cohort as a covariate demonstrated fundamentally consistent results between the new and original grouping. About $99.1 \%$ of children exhibited the same pattern of obesity trajectories between the new and original grouping (agreement rate was $99.1 \%$ and Kappa was 0.973), suggesting that different birth cohorts are less likely to bias the findings of the study.

Second, the current study focuses on examination of associations of individual-level characteristics, experiences and risk behaviors with obesity, without comprehensive examinations of familial-level factors, including characteristics of mothers and families. Our preliminary analyses indicated that birth order of child was not significantly associated with obesity trajectories; but mother's age at child's birth and family's average annual income were significantly associated with obesity trajectories. Children who were born to young mothers ( $\leq 9$ years old) and those living with a higher family income had a lower likelihood of becoming obese from childhood to adolescence. These findings suggest that family characteristics may contribute to high risk obesity trajectory. Examinations of associations of characteristics of parents and families with obesity constitute important areas that warrant additional studies.

Third, there were multiple children from a household; the 5,156 children were born to 2,648 mothers. Mothers had an average of two children, with a range of 1 to 7 children. Sibling effect was not controlled in the analysis because group-based trajectory modeling is aimed to examine person-centered trajectory by assuming individuals have their own developmental processes across age. Siblings are assumed to have their own unique developmental pathways. A sensitivity analysis including number of siblings within a household as a covariate in trajectory modeling indicated that patterns of trajectories and percentage of children in each trajectory group were essentially alike between the new and the original analysis, suggesting that the sibling effect is less likely to result in a bias in the findings.

Moreover, self-report, as opposed to measured BMI, was used. However, only minor differences in reliability between self-reported and measured BMI have been indicated among children and adolescents (Sherry, Jefferds, \& Grummer-Strawn, 2007). Finally, incidence of risk behaviors based upon self-report are likely to be underestimated 
(Shillington \& Clapp, 2000). However, sensitive questions regarding children's behaviors were administered with the Computer Assisted Personal Interview (CAPI), which improves the reliability of responses (Baker, Bradburn \& Johnson, 1995).

\section{Conclusions}

Using a large, nationwide sample of children, this study found that obesity trajectories across childhood and adolescence were differentially related to psychosocial health and, to a lesser extent, risk behavior trends across adolescence. Results have public health implications for developing improved strategies for obese adolescents at risk for poorer psychosocial health and problem behaviors, particularly increased cigarette smoking. In addition to targeting chronically obese adolescents for cigarette smoking, specific efforts should be focused on those moving from non-obese to obese status during early adolescence. This subgroup of adolescents appears to be particularly vulnerable to adverse psychosocial health. A developmentally appropriate and comprehensive intervention program, as well as smoking cessation and psychosocial management may be particularly beneficial.

\section{Acknowledgments}

This study is supported by Grant Number R03HD064619 from the Eunice Kennedy Shriver National Institute of Child Health \& Human Development and partially supported by the University of California, Los Angeles, Center for Advancing Longitudinal Drug Abuse Research (CALDAR) under Grant P30DA016383 from the National Institute on Drug Abuse (NIDA) and the University of California, Los Angeles, Drug Abuse Research Training Center sponsored by NIDA (5T32DA007272-19). The content is solely the responsibility of the authors and does not necessarily represent the official views of the funders or the National Institutes of Health.

\section{References}

Arkes J. Longitudinal association between marital disruption and child BMI and obesity. Obesity. (epublished ahead of print, 2012).

Baker RP, Bradbun NM, Johnson RA. Computer-assisted personal interviewing: An experimental evaluation of data quality and cost. Journal of Official Statistics. 1995; 11:413-431.

Barlow SE. The Expert Committee. Expert Committee recommendation regarding the prevention, assessment, and treatment of child and adolescent overweight and obesity: Summary. Pediatrics. 2007; 120:S164-S192. [PubMed: 18055651]

Brown, B. Adolescents relationships with peers. In: Lerner, R.; Steinberg, L., editors. Handbook of Adolescent Psychology. 2nd ed. New York: Wiley; 2004. p. 363-394.

Byrne DG, Byrne AE, Reinhart MI. Personality, stress and the decision to commence smoking in adolescence. Journal of Psychosomatic Research. 1995; 39:53-62. [PubMed: 7760303]

Caprio S, Daniels SR, Drewnowski A, Kaufman FR, Palinkas LA, Rosenbloom AL, Schwimmer JB. Influence of race, ethnicity, and culture on childhood obesity: Implications for prevention and treatment. Diabetes Care. 2008; 31:2211-2221. [PubMed: 18955718]

Caria MP, Bellocco R, Zambon A, Horton NJ, Galanti MR. Overweight and perception of overweight as predictors of smokeless tobacco use and of cigarette smoking in a cohort of Swedish adolescents. Addiction. 2009; 104:661-668. [PubMed: 19215597]

Cawley J, Markowitz S, Tauras J. Lighting up and slimming down: The effects of body weight and cigarette prices on adolescent smoking initiation. Journal of Health Economics. 2004; 23:293-311. [PubMed: 15019756]

Craig LCA, Love J, Ratcliffe B, McNeill G. Overweight and cardiovascular risk factors in 4- to 18year-olds. Obesity Facts. 2008; 1:237-242. [PubMed: 20054184]

Crosnoe R, Muller C. Body mass index, academic achievement, and school context: Examining the educational experiences of adolescents at risk of obesity. Journal of Health and Social Behavior. 2004; 45:393-407. [PubMed: 15869112] 
Farhat T, Iannotti RJ, Morton-Simons BG. Overweight, obesity, youth, and health-risk behaviors. American Journal of Preventive Medicine. 2010; 38:258-267. [PubMed: 20171527]

Fonseca H, Matos MG, Guerra A, Pedro JG. Are overweight and obese adolescents different from their peers? International Journal of Pediatric Obesity. 2009; 4:166-174. [PubMed: 19051091]

Gordon-Larsen P, Adair LS, Popkin BM. The relationship of ethnicity, socioeconomic factors, and overweight in U.S. adolescents. Obesity Research. 2003; 11:121-129. [PubMed: 12529494]

Haney P, Durlak JA. Changing self-esteem in children and adolescents: A meta-analyrical review. Journal of Clinical Child Psychology. 1998; 27:423-433. [PubMed: 9866079]

Ho C, Kingree JB, Thompson MP. Associations between juvenile delinquency and weight-related variables: Analyses from a national sample of high school students. International Journal of Eating Disorders. 2006; 39:477-483. [PubMed: 16637048]

Jones BL, Nagin DS, Roeder K. A SAS procedure based on mixture models for estimating developmental trajectories. Sociological Methods and Research. 2001; 29(3):374-394.

Kobus K. Peers and adolescent smoking. Addiction. 2003; 98:37-55. [PubMed: 12752361]

Kuczmarski RJ, Ogden CL, Grummer-Strawn LM, Flegal KM, Guo SS, Wei R, et al. CDC Growth Charts: United States advance data from vital and health statistics. No. 314. National Center for Health Statistics. 2000

LaFontana KM, Cilleseen AHN. Developmental changes in the priority of perceived status in childhood and adolescence. Social Development. 2010; 19:130-147.

Langenkamp AG, Frisco ML. Family transitions and adolescent severe emotional distress: The salience of family context. Social Problems. 2008; 55:238-253.

Leatherdale ST, Wong SL, Manske SR, Colditz GA. Susceptibility to smoking and its association with physical activity, BMI, weight concerns among youth. Nicotine \& Tobacco Research. 2008; 10:499-505. [PubMed: 18324569]

Li C, Goran MI, Kaur H, Nollen N, Ahluwalia JS. Developmental trajectories of overweight during childhood: Role of early life factors. Obesity. 2007; 15:760-771. [PubMed: 17372328]

Lloyd DA, Taylor J. Lifetime cumulative adversity, mental health and the risk of becoming a smoker. Health. 2006; 10:95-122. [PubMed: 16322045]

Lowry R, Galuska DA, Fulton JE, Wechsler H, Kann L. Weight management goals and practices among U.S. high school students: Associations with physical activity, diet, and smoking. Journal of Adolescent Health. 2002; 31:133-144. [PubMed: 12127383]

McVey GL, Davis R, Tweed S, Shaw BF. Evaluation of a school-based program designed to improve body image satisfaction, global self-esteem, and eating attitudes and behaviors: A replication study. International Journal of Eating Disorders. 2004; 36:1-11. [PubMed: 15185266]

Mustillo S, Worthman C, Erkanli A, Keeler G, Angold A. Obesity and psychiatric disorder: Developmental trajectories. Pediatrics. 2003; 111:851-859. [PubMed: 12671123]

Nagin, DS. Group-based modeling of development. Cambridge, MA: Harvard University Press; 2005.

Needham BL, Epel ES, Adler NE, Kiefe C. Trajectories of change in obesity and symptoms of depression: The CARDIA study. American Journal of Public Health. 2010; 100:1040-1046. [PubMed: 20395582]

Nonnemaker JM, Morgan-Lopez AA, Pais JM, Finkelstein EA. Youth BMI trajectories: Evidence from the NLSY97. Obesity. 2009; 17:1274-1280. [PubMed: 19584884]

Oesterle S, Hill KG, Hawkins JD, Guo J, Catalano RF, Abbott RD. Adolescent heavy episodic drinking trajectories and health in young adulthood. Journal of studies on Alcohol. 2004; 65:204212. [PubMed: 15151351]

Ogden CL, Carroll MD, Curtin LR, Lamb MM, Flegal KM. Prevalence of high body mass index in US children and adolescents, 2007-2008. Journal of the American Medical Association. 2010; 303:242-249. [PubMed: 20071470]

Oldehinkel AJ, Ormel J, Veenstra R, De Winter AF, Verhulst FC. Parental divorce and offspring depressive symptoms: Dutch developmental trends during early adolescence. Journal of Marriage and Family. 2008; 70:284-293.

Oliver G, Wardle J, Gibson L. Stress and food choice: A laboratory study. Psychosomatic Medicine. 2000; 62:853-865. [PubMed: 11139006] 
Pasch KE, Nelson MC, Lytle LA, Moe SG, Perry CL. Adoption of risk-related factors through early adolescence: Associations with weight status and implications. Journal of Adolescent Health. 2008; 43:387-393. [PubMed: 18809137]

Pearce MJ, Boergers J, Prinstein MJ. Adolescent obesity, overt, and relational peer victimization, and romantic relationships. Obesity Research. 2002; 10:386-393. [PubMed: 12006638]

Pearlin LI, Menagham EG, Lieberman MA, Mullan JT. The stress process. Journal of Health and Social Behavior. 1981; 22:337-356. [PubMed: 7320473]

Pine DS, Wasserman G, Coplan J, Staghezza-Jaramillo B, Davies M, Fried JE, et al. Cardiac profile and disruptive behavior in boys at risk for delinquency. Psychosomatic Medicine. 1996; 58:342353. [PubMed: 8827797]

Potter BK, Pederson LL, Chan SS, Aubut JA, Koval JJ. Does a relationship exist between body weight, concerns about weight, and smoking among adolescents? An integration of the literature with an emphasis on gender. Nicotine \& Tobacco Research. 2004; 6:397-425. [PubMed: 15203775]

Ratcliff MB, Jenkins TM, Reiter-Purtill J, Noll JG, Zeller MH. Risk-taking behaviors of adolescents with extreme obesity: Normative or not? Pediatrics. 2011; 127:827-834. [PubMed: 21518723]

Radloff LS. The CES-D scale: A self-report depression scale for research in the general population. Applied Psychological Measurement. 1997; 1:385-401.

Rhee KE, Lumeng JC, Appugliese DP, Kaciroti N, Bradley RH. Parenting style and overweight status in first grade. Pediatrics. 2006; 117:2047-2054. [PubMed: 16740847]

Rosenberg, M. Society and the adolescent self-image. Princeton: Princeton University Press; 1965.

Rosenbloom A, Arslanian S, Brink S, Conschafter K, Jones KL, Klingensmith G, et al. Type 2 diabetes in children and adolescents. Pediatrics. 2000; 105:671-680. [PubMed: 10699131]

Schiffman SS, Graham BG, Sattely-Miller EA, Peterson-Dancy M. Elevated and sustained desire for sweet taste in African-Americans: A potential factor in the development of obesity. Nutrition. 2000; 16:886-893. [PubMed: 11054593]

Schwartz G. Estimating the dimension of a model. The Annals of Statistics. 1978; 6:461-464.

Sherry B, Jefferds ME, Grummer-Strawn LM. Accuracy of adolescent self-report of height and weight in assessing overweight status: A literature review. Archives of Pediatrics and Adolescent Medicine. 2007; 161(12):1154-1161. [PubMed: 18056560]

Shillington AM, Clapp JD. Self-report of adolescent substance use: are there differences for gender, ethnicity and age? Drug and Alcohol Dependence. 2000; 60:19-27. [PubMed: 10821986]

Steinberg L. A social neuroscience perspective on adolescent risk-taking. Developmental Review. 2008; 28:78-106. [PubMed: 18509515]

Strauss RS, Pollack HA. Social marginalization of overweight children. Archives of Pediatric Adolescent Medicine. 2003; 157:746-752.

Sweeting H, Wright C, Minnis H. Psychosocial correlates of adolescent obesity, 'slimming down' and 'becoming obese'. Journal of Adolescent Health. 2005; 37:409.e9-409.e17. [PubMed: 16227129]

Torres S, Nowson C. Relationship between stress, eating behavior and obesity. Nutrition. 2007; 23:887-894. [PubMed: 17869482]

U.S. Department of Labor, Bureau of Labor Statistics. The NLSY79 Children and Young Adults. 2011. Retrieved May 18, 2011, from http://www.bls.gov/nls/nlsy79ch.htm.

Ventura AK, Loken E, Birch LL. Developmental trajectories of girls' BMI across childhood and adolescence. Obesity. 2009; 17:2067-2074. [PubMed: 19424165]

Wills TA, Sandy JM, Yaeger AM. Stress and smoking in adolescence: A test of directional hypotheses. Health Psychology. 2002; 21:122-130. [PubMed: 11950102]

Zeller MH, Reiter-Putrill J, Ramey C. Negative peer perceptions of obese children in the classroom environment. Obesity. 2008; 16:755-762. [PubMed: 18379560] 


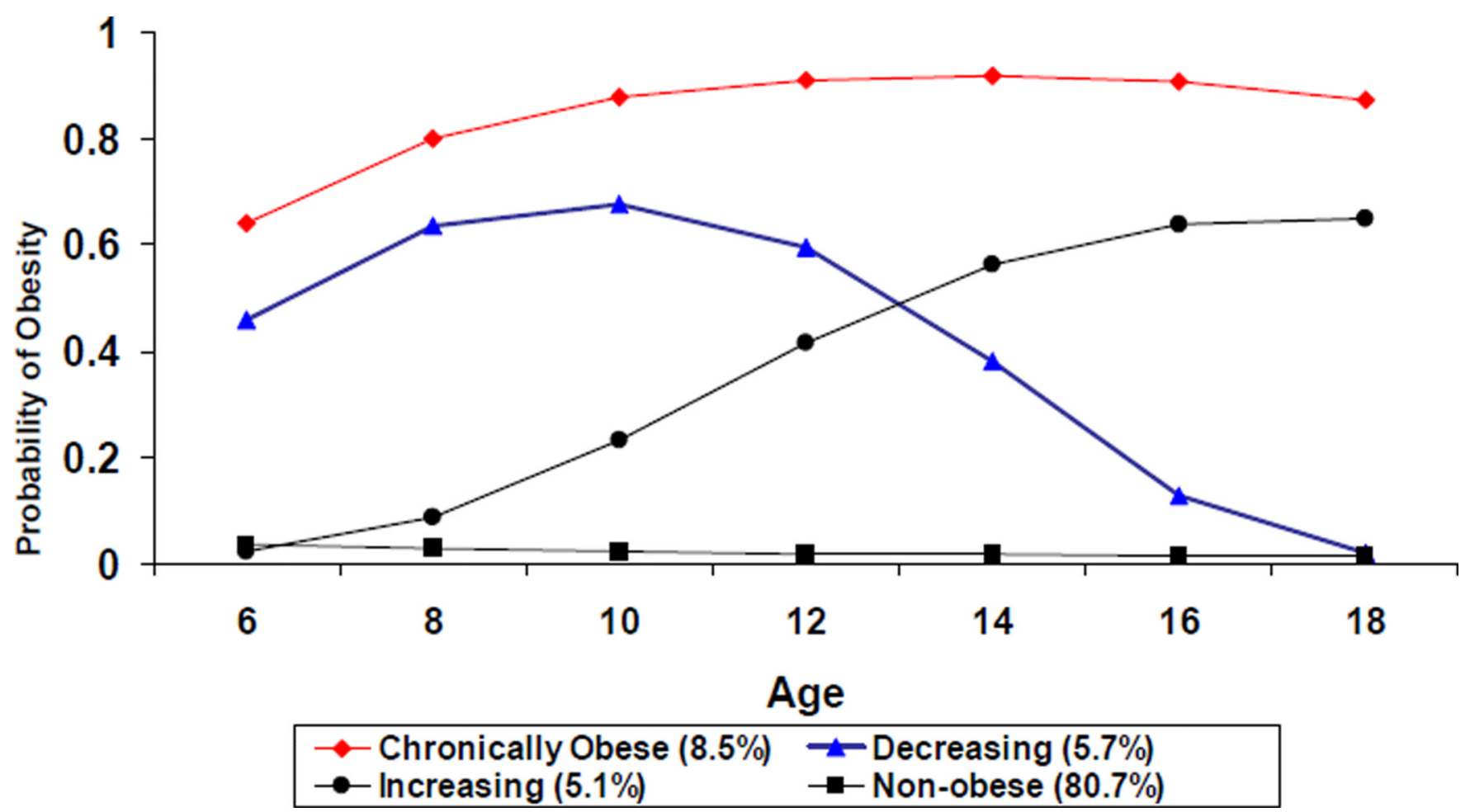

Figure 1.

Trajectories of Obesity (BMI percentile $>=95 \%$ ) 
A. Probability of Alcohol Use
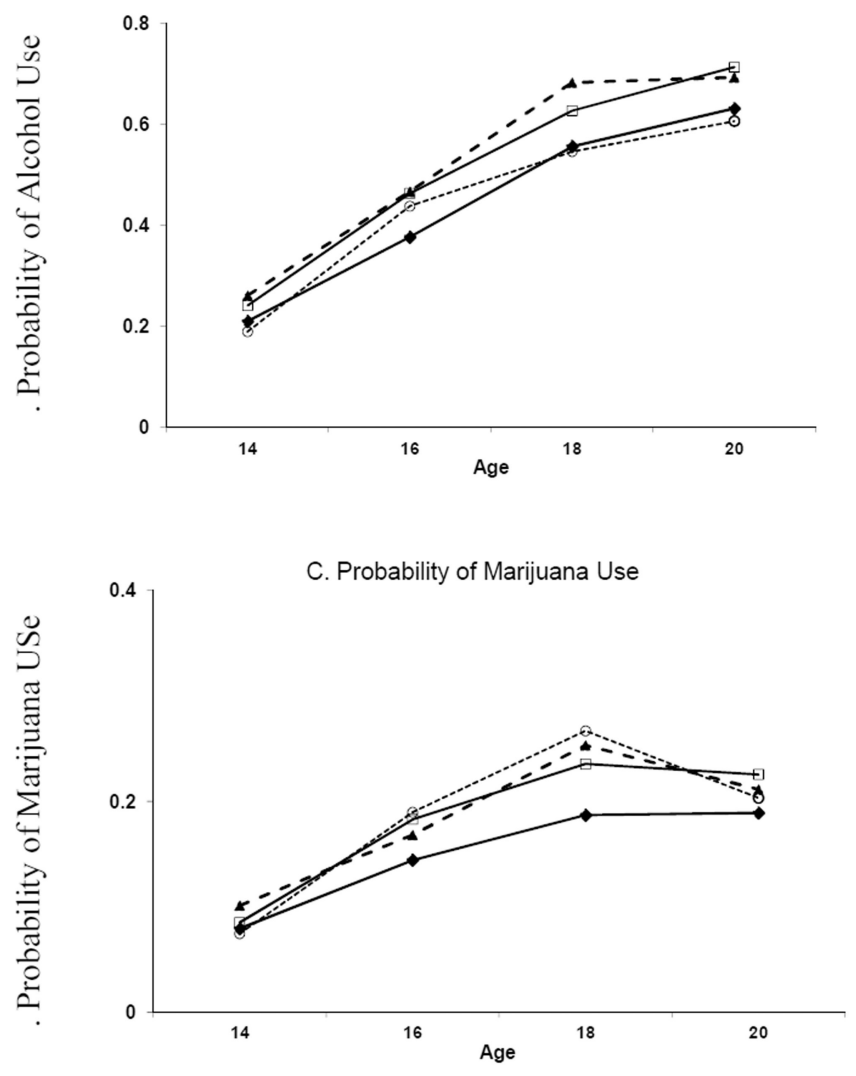

$\neg$ Chronically Obese $(8.5 \%)$ -๑--Increasing (5.1\%)
B. Probability of Smoking

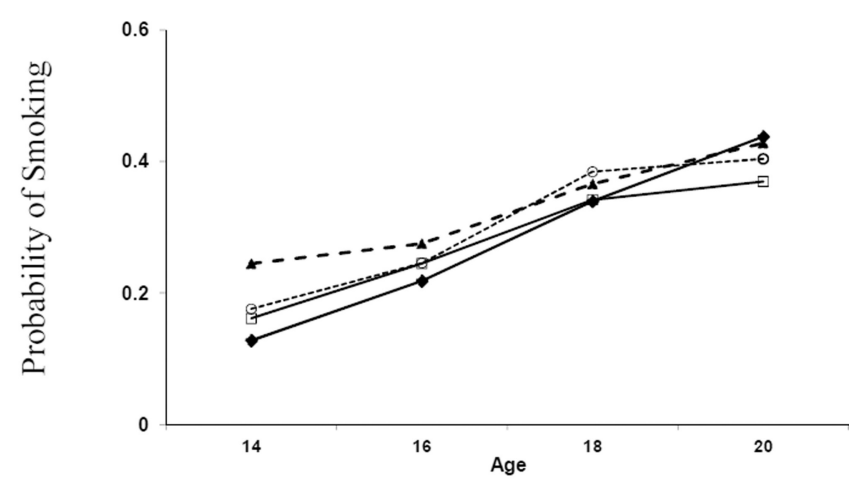

D. Probability of Delinquency

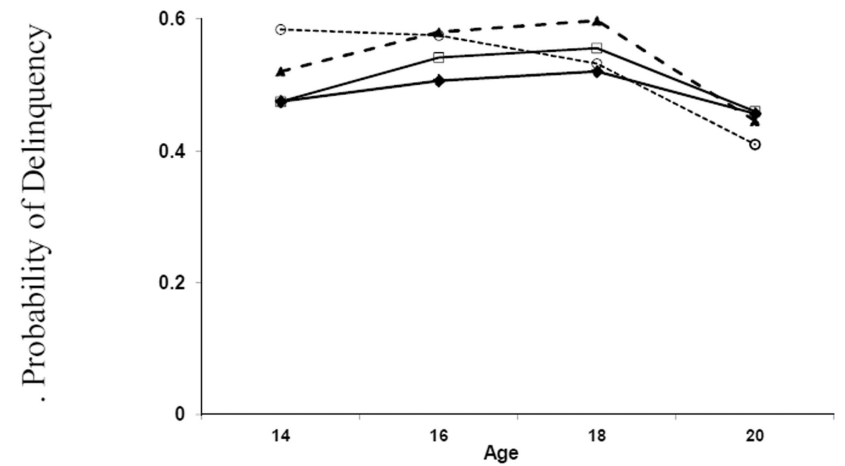

Figure 2.

Probability of Risk Behaviors from Ages 14 to 20 by the Obesity Groups 
Table 1

Effective Sample Size at Each Age

\begin{tabular}{cc}
\hline Age & $\begin{array}{c}\text { Number of } \\
\text { children }\end{array}$ \\
\hline 6 & 4,196 \\
8 & 4,594 \\
10 & 4,765 \\
12 & 4,697 \\
14 & 4,643 \\
16 & 4,639 \\
18 & 4,346 \\
\hline
\end{tabular}




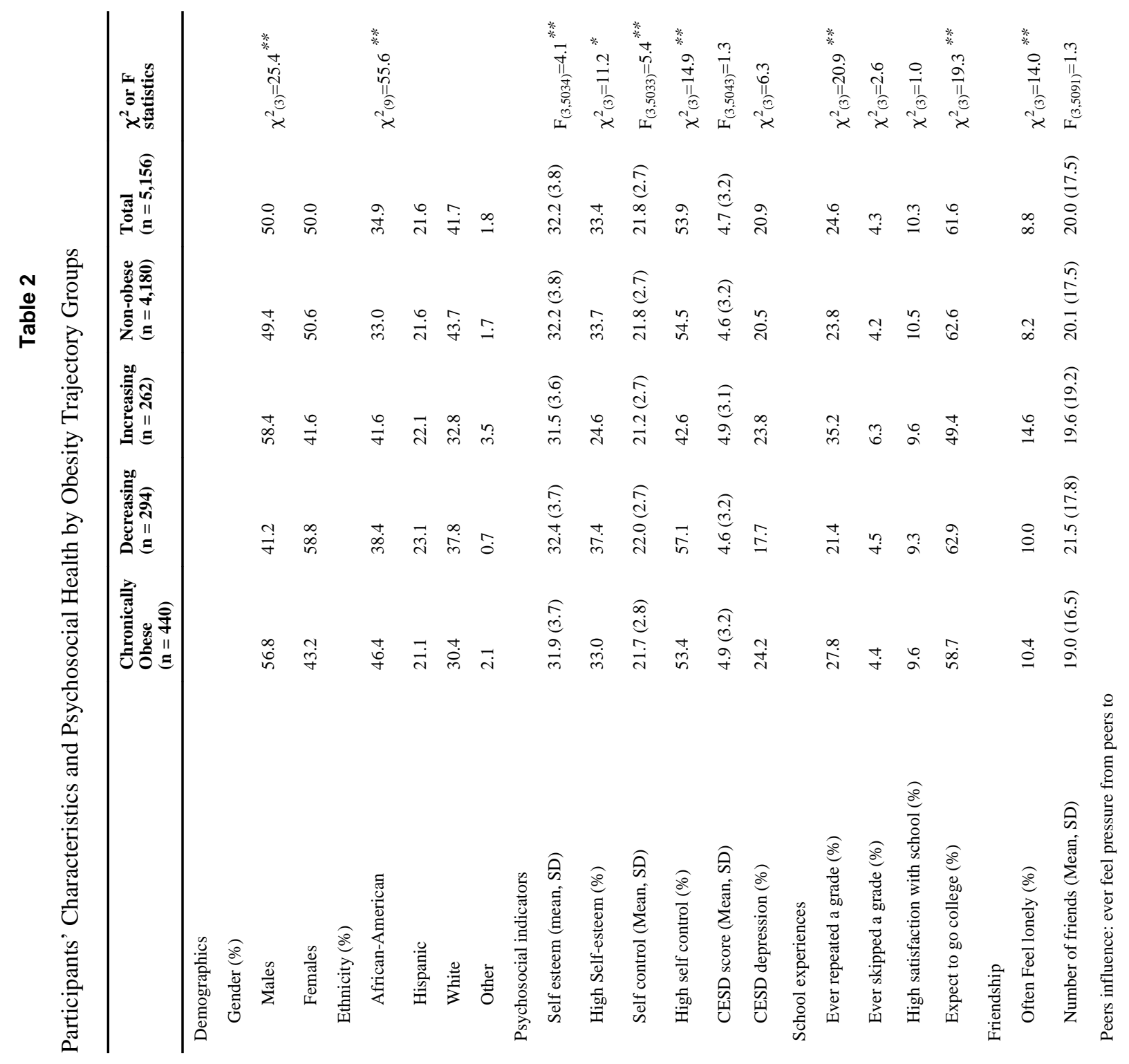




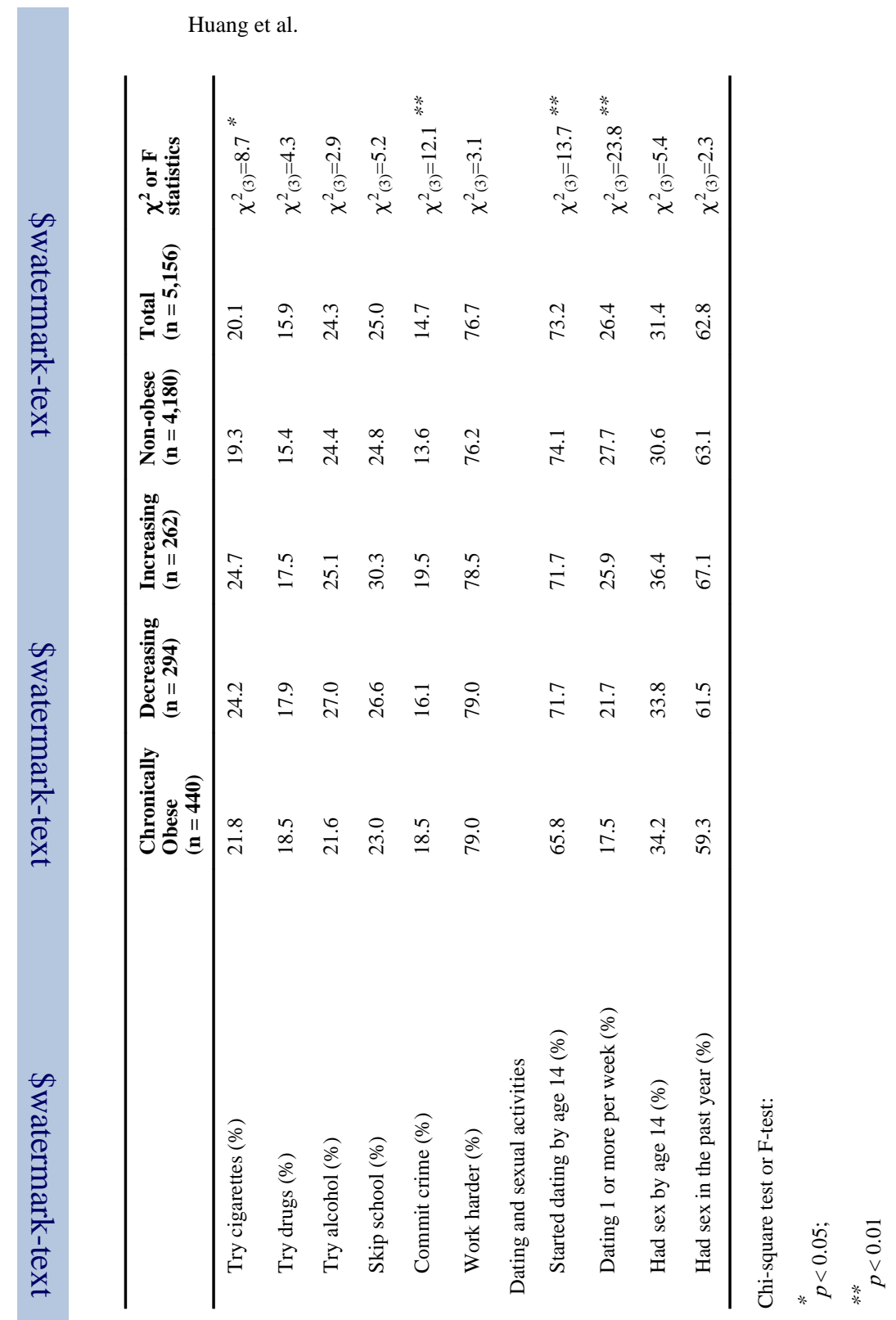




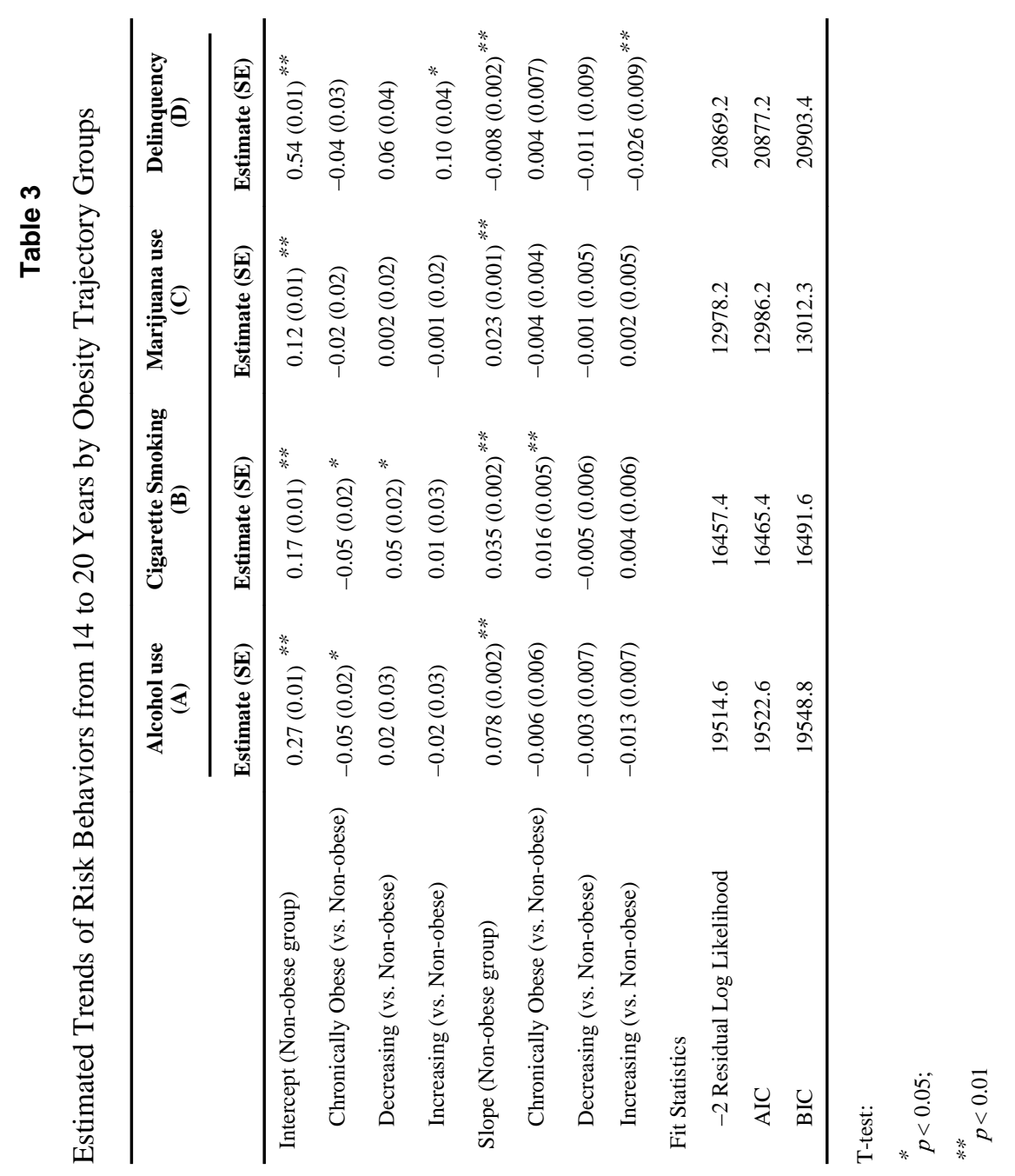

